\title{
On measurement of mechanical properties of sound absorbing materials
}

\author{
N. DAUCHEZ \\ Centre de Transfert de Technologie du Mans (CTTM), Technopole Université, 72000, Le Mans, France
}

M. ETCHESSAHAR \& S. SAHRAOUI

Laboratoire d'Acoustique de l'Université du Maine (UMR CNRS 6613), Avenue Olivier Messiaen, 72085, Le Mans Cedex 9, France

ABSTRACT: This paper is an overview of quasistatic measurement technique used to determine mechanical properties of sound absorbing materials. Experimental context and behaviour of polymer foam and rock wool are summarized. Concerning parameters are: static and dynamic strains, dynamic effects such as skeleton resonance and coupling with saturating fluid. Material anisotropy and frequency dependance of characteristics are also addressed. It is shown that this technique is well suited for usual material up to $100 \mathrm{~Hz}$. Restrictions occurs for thin samples of very high air flow resistivity and for fibrous material that do not exhibit a linear behaviour with static strain.

\section{INTRODUCTION}

Measurement of the mechanical properties of sound absorbing materials such as plastic foams and glass wools are shown to be complex due to frequency and dynamic strain dependances (Pritz 1986, Pritz 1994). This paper deals with mechanical response of such materials in function of static and dynamic strains and frequency, in order to specify suitable experimental conditions. Anisotropy and validity of quasistatic hypothesis are discussed.

\section{DESCRIPTION OF THE MEASUREMENT SET-UP}

Measurement of mechanical properties of sound absorbing materials described by Biot theory is performed using a quasistatic set-up (Sahraoui et al. 2001a).

The measurement set-up is depicted on figure 1. It is based on small amplitude sinusoidal compression of a cubic porous sample between two rigid plates. In order to insure the contact between the sample and the moving plate, sample is slightly strained. Then controlled amplitude harmonic excitation is performed by a shaker. The quasistatic frequency range is restricted to frequencies which are far below the resonance of the sample, typically from $1 \mathrm{~Hz}$ to $100 \mathrm{~Hz}$. In this low frequency range, inertial and viscous coupling with the air are neglected.

Applied force $F(\omega)$, longitudinal displacement $u_{L}(\omega)$ of the moving plate, and displacements at the centre of lateral faces $u_{T}(\omega), u_{T^{\prime}}(\omega)$ are monitored as function of frequency (Figure 1). Three transfer functions are computed:

$K(\omega)=\frac{F(\omega)}{u_{L}(\omega)}$

is a longitudinal stiffness and

$T(\omega)=\frac{u_{T}(\omega)}{u_{L}(\omega)}, \quad T^{\prime}(\omega)=\frac{u_{T^{\prime}}(\omega)}{u_{L}(\omega)}$,

are two displacements ratios, homogeneous to Poisson's ratio.

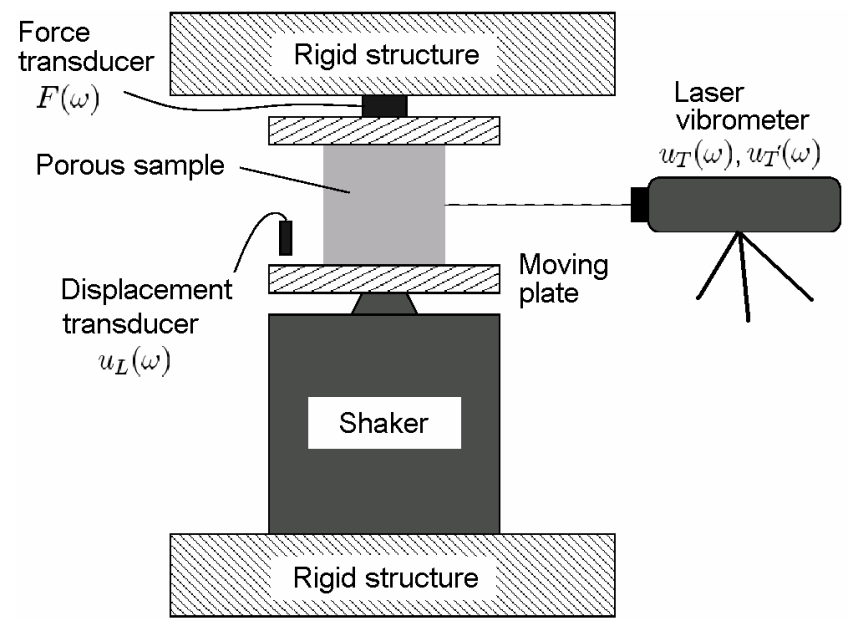

Figure 1. Mechanical properties measurement set-up.

Calibration of measurement set-up is performed for $K(\omega)$ function by measuring frequency response of a reference spring of known stiffness and mass. Its damping is assumed to be $1 \%$. Compensation of spring dynamic response is effective after 10 $\mathrm{Hz}$.

Calibration for $T(\omega)$ function is performed by a simultaneous measurement of moving plate displacement by both transducers.

\section{CHARACTERISATION OF ACOUSTICAL POROUS MATERIALS}

The influence of experimental parameters is studied for two representative acoustical porous materials: a polymer foam and a rock wool. Acoustical parameters, according to Biot-Allard theory (Allard 1993), are given in table 1. Samples are $40 \mathrm{~mm}$ thick cubes.

Table 1. Acoustic parameters of tested materials.

\begin{tabular}{lllll}
\hline Material & Porosity & $\begin{array}{l}\text { Resistivity } \\
\text { N.s.m }\end{array}$ & Tortuosity & $\begin{array}{l}\text { Density } \\
\text { kg.m }\end{array}$ \\
\hline $\begin{array}{l}\text { Polymer } \\
\text { foam }\end{array}$ & 0.97 & 165000 & 1.8 & 39.5 \\
\hline $\begin{array}{l}\text { Rock } \\
\text { wool }\end{array}$ & 0.98 & 16500 & 1.1 & 21 \\
\hline
\end{tabular}




\subsection{Influence of static and dynamic strain amplitude}

Sample stiffness is studied as a function of static $\mathcal{E}_{s}$ and dynamic $\mathcal{E}_{d}$ strains, so that imposed strain is

$\varepsilon(t)=\varepsilon_{s}+\varepsilon_{d} \sin (\omega t)$.

First, the influence of the amplitude of dynamic strain is studied. Measurement is performed at $100 \mathrm{~Hz}$ for a static strain of $2 \%$. Figure 2 shows results for polymer foam (grey squares): stiffness and loss factor are constant under $0.05 \%$ dynamic strain. Then stiffness decreases and loss factor increases. The same behaviour is observed on figure 3 for rock wool. This confirms Pritz work (Pritz 1986, Pritz 1994) that mentions non linearity past $0.05 \%$.

The influence of the amplitude of static strain is now studied. Measurement is performed at $100 \mathrm{~Hz}$ for $0.02 \%$ dynamic strain. Figure 2 shows results for polymer foam (black circles). First, stiffness increases quickly with static amplitude, as long as surface cells, damaged by cutting, are compressed. Then stiffness reaches a plateau, corresponding to linearity zone: related value is considered to be the actual stiffness of material. For higher amplitudes, stiffness decreases due to buckling of cells. In the same way, loss factor first decreases and then reaches a stable value considered as actual material loss factor.

Figure 3 shows a different behaviour for fibrous material. Stiffness always increases without reaching a stable value, due to collapsing of fibres. No clear tendency is observed for loss factor. No linearity zone can be found.

Measurement of stiffness and loss factor are performed using a dynamic strain less than $0.05 \%$. For polymer foam, static strain is increasing step by step in order to reach linearity zone. This procedure is repeated for every sample. For fibrous material, measurement is performed using a static strain as close as possible to use conditions.
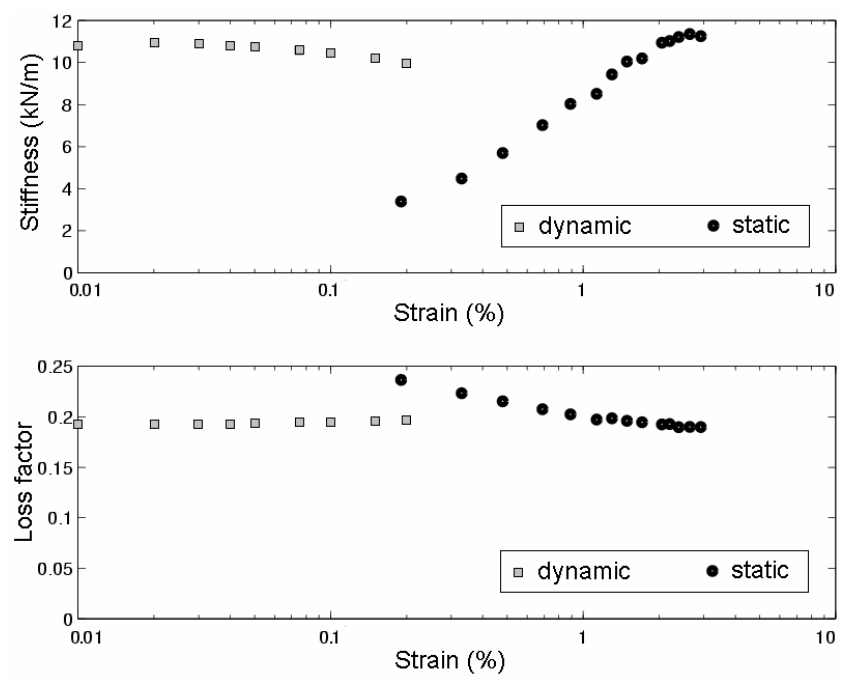

Figure 2. Influence of dynamic (at static strain $=2 \%$ ) and static strain (at dynamic strain $=0.02 \%$ ) on measured stiffness and loss factor of polymer foam.
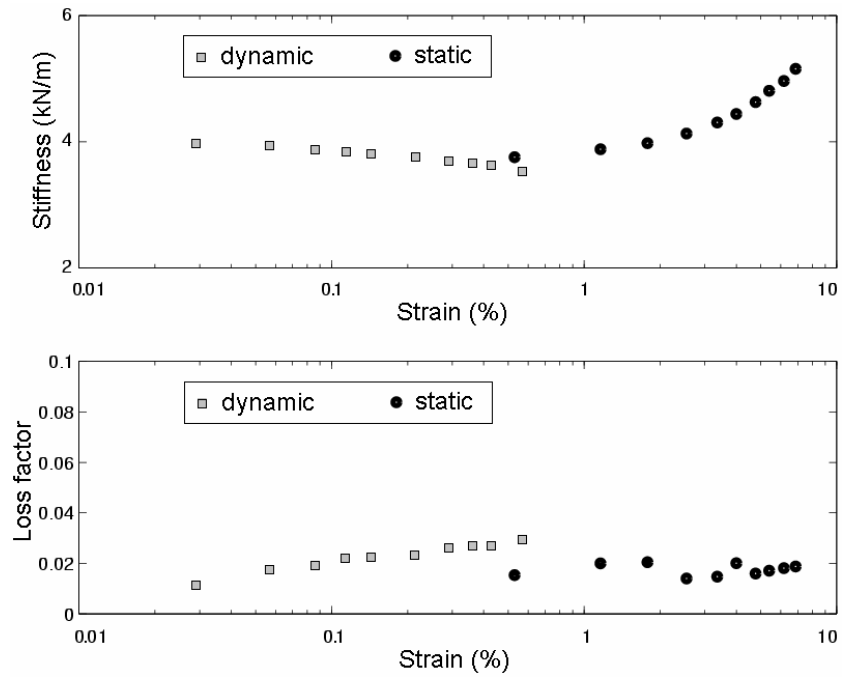

Figure 3. Influence of dynamic (at static strain $=1.2 \%$ ) and static strain (at dynamic strain $=0.085 \%$ ) on measured stiffness and loss factor of rock wool.

\subsection{Anisotropy}

In order to analyse anisotropy of porous materials, cubic samples are tested. By positioning the sample according to each direction, three triplets $K(\omega), T(\omega), T^{\prime}(\omega)$ are determined. If the three triplets are identical and $T(\omega)=T^{\prime}(\omega)$ for each direction, the tested material is isotropic. Only in these conditions, Young's modulus and Poisson's ratio can be determined. For a sample of base surface $S$ and thickness $L$, they are related to functions of Poisson's ration $v, h(v)$ and $g(v)$ by

$T(\omega)=g(v)$,

$K(\omega)=\frac{E(\omega)(1-v) S / L}{h(v)}$

These functions can be computed using a finite elements code. They are presented in figure 4 for a cubic sample.

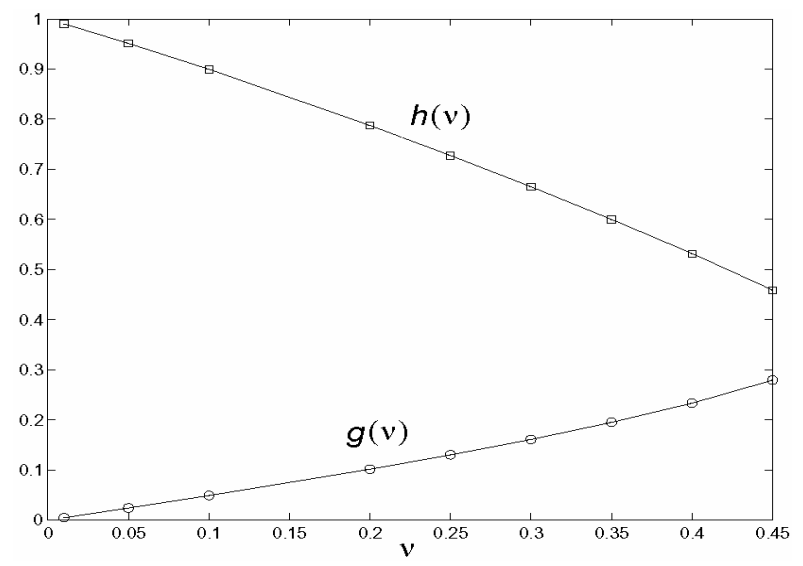

Figure 4. $h(v)$ and $g(v)$ functions.

Measurements performed at LAUM show that polymer foams are anisotropic in most cases (Melon et al. 1998). Isotropic law is then no more suitable. Axisymmetrical law is usu- 
ally assumed, but much more complicated to implement. For usual applications, Dauchez et al. show that isotropic law can give good results (Dauchez et al. 2000): a pseudo Young's modulus and a pseudo Poisson's ratio are determined from transfer functions measured in the direction corresponding to actual use of material.

\subsection{Frequency dependance of characteristics}

Frequency dependance of Young's modulus and loss factor of polymer foams have been studied by various authors (Pritz 1994, Mariez et al. 1997, Sfaoui 1995).

Figure 5 and 6 present experimental results for an anisotropic polymer foam. It is shown that frequency dependances are the same for each direction. Poisson's ratio is real and constant with frequency. These results confirm structural model prediction (Sahraoui et al. 2001b): Poisson's ratio only depends on the microstructure of material, whereas Young's modulus and loss factor also depends on polymer characteristics.
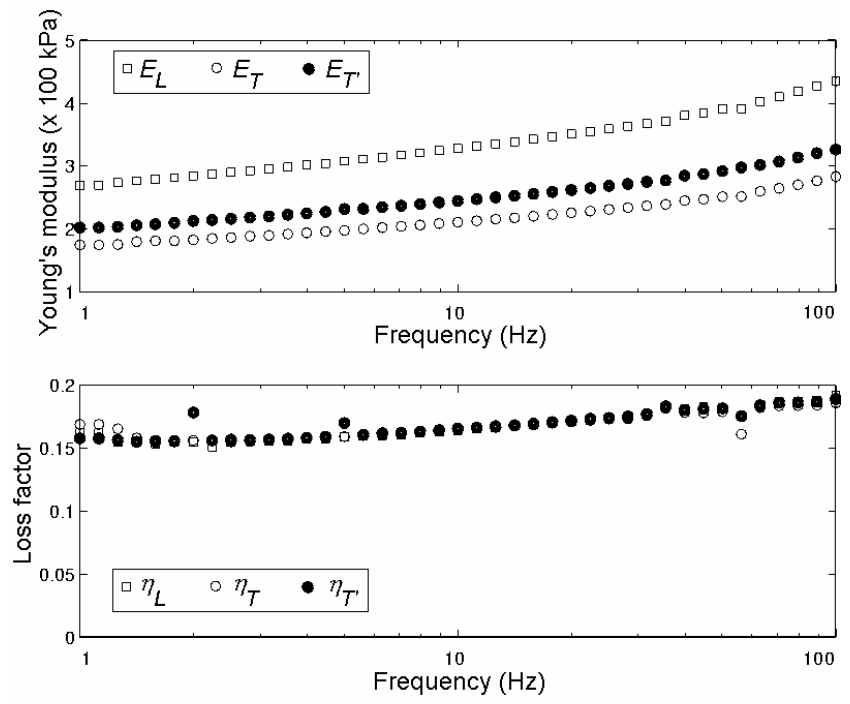

Figure 5. Longitudinal and transversal Young's modulus and loss factors of polymer foam.
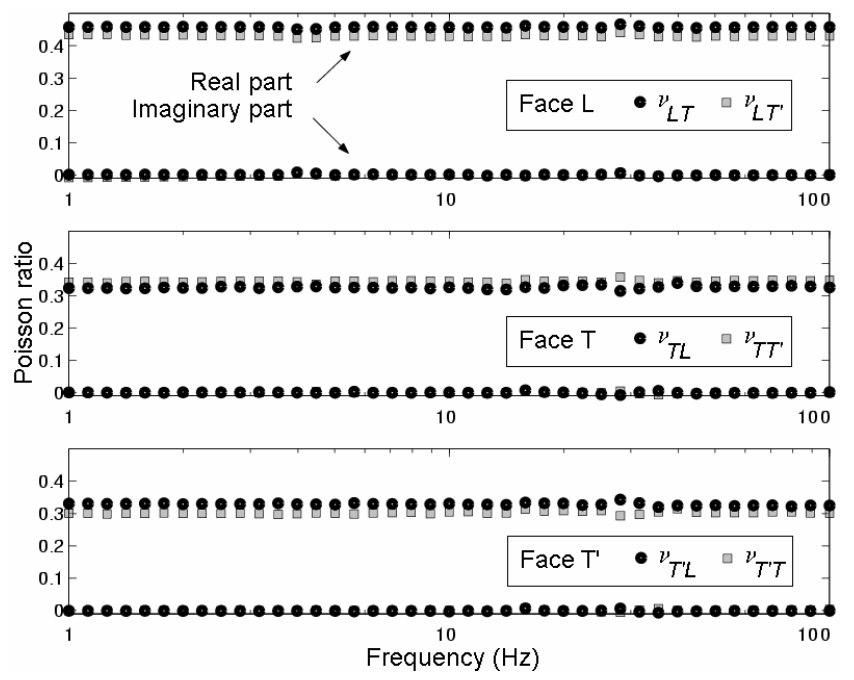

Figure 6. Poisson's ratios of polymer foam.
Fibrous materials have most of fibres parallel to the material plane. Poisson's ratio, determined from normal compression of material, is then close to zero (Sides et al., 1971) and no frequency dependant. Measurement of Young's modulus and loss factor in the normal direction is presented in figure 7: they are not frequency dependant, as observed by Pritz (Pritz 1986). This result is valid only if fibres are not binding by a polymer agent.
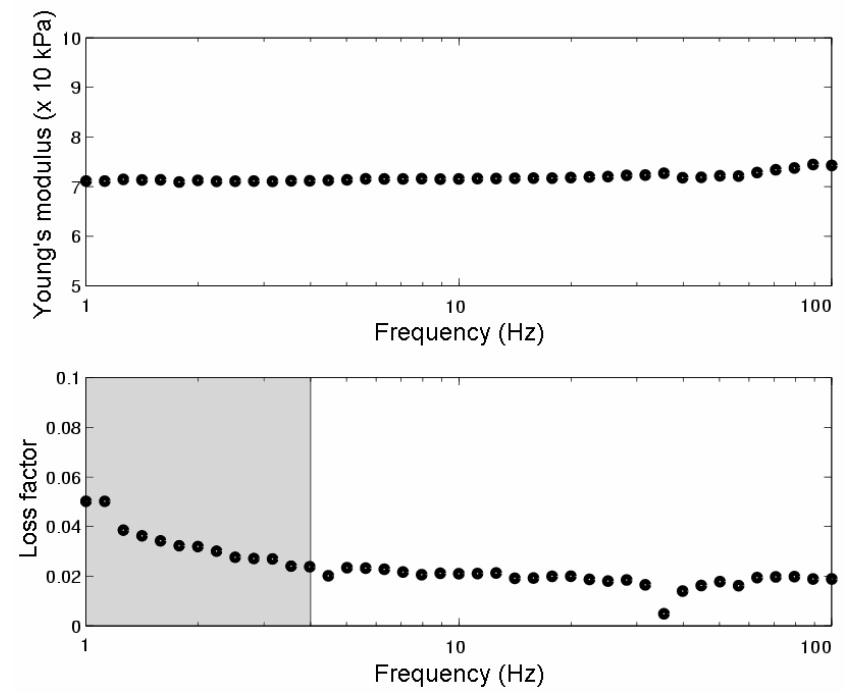

Figure 7. Young's modulus and loss factor of rock wool (Shaded part corresponds to improper data due to insufficient transducer sensitivity).

\subsection{Validity of quasistatic hypothesis}

Quasistatic hypothesis are: dynamic influence of skeleton inertia and influence of saturating fluid can be neglected over the whole frequency range $1 \mathrm{~Hz}-100 \mathrm{~Hz}$. These hypotheses are verified using a finite element code with poroelastic elements (Panneton et al. 1997). The experimental conditions are simulated by: a clamped solid plate used as force sensor, a square base $(S=50 \mathrm{~mm} \times 50 \mathrm{~mm})$ porous sample of thickness $h$, a moving solid plate. Porous sample characteristics are: porosity 0.98 , resistivity $10^{3}$ to $10^{7} \mathrm{Nsm}^{-4}$, tortuosity 1.3 , density 30 $\mathrm{kg} \cdot \mathrm{m}^{-3}$, Young's modulus $100 \mathrm{kPa}$, loss factor 0.1 , Poisson's ratio 0.3 , thickness $10 \mathrm{~mm}$ or $50 \mathrm{~mm}$. Boundary conditions are : no transversal displacement of skeleton in contact with the plates, free displacement of the fluid and skeleton elsewhere. Fluid in the porous media is not loaded by external fluid.

Figures 8 and 9 present predicted stiffness, normalized to base surface $S$ and thickness $h$, for several air flow resistivities and for two thicknesses. Dynamic effect is shown mainly on real part and for thicker sample after $100 \mathrm{~Hz}$ : mechanical impedance decreases near sample first resonance. Coupling effect with fluid can be shown after $10 \mathrm{~Hz}$ for strong resistivities higher than $10^{6} \mathrm{Nms}^{-4}$. Effect on real part corresponds to added stiffness, and effect on imaginary part corresponds to added damping. This latter effect comes to lower frequencies.

For common materials and cubic samples, quasistatic hypothesis is valid. Special care has to be taken for thin and very resistive materials. This fact is confirmed by a measurement 
performed on a fibrous sample: diameter $44 \mathrm{~mm}$, thickness 8.5 $\mathrm{mm}$, resistivity $240 \mathrm{kNsm}^{-4}$. Figure 10 shows a sharp increasing loss factor after $10 \mathrm{~Hz}$ and of Young's modulus after $50 \mathrm{~Hz}$.

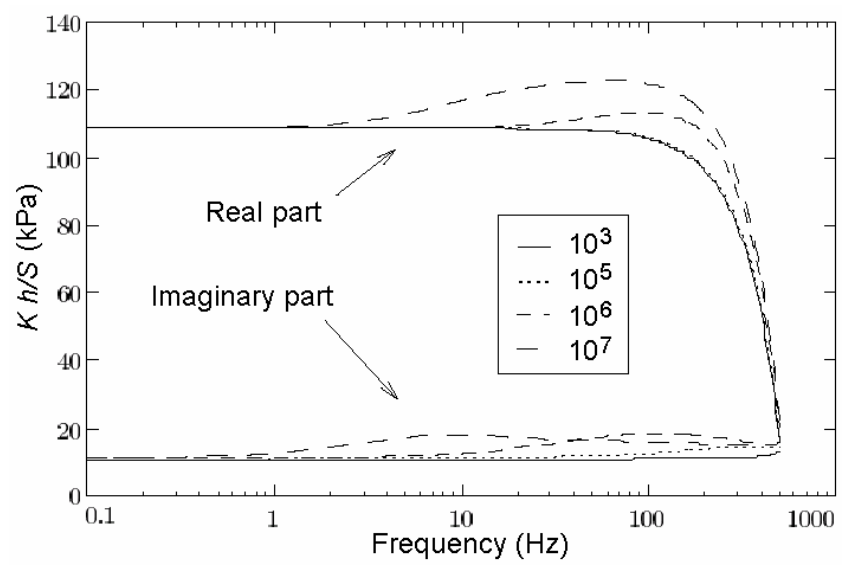

Figure 8. Predicted stiffness $K(\omega)$ for several air flow resistivities $\left(\mathrm{Nsm}^{-4}\right)$ of $50 \mathrm{~mm}$ thick porous sample.

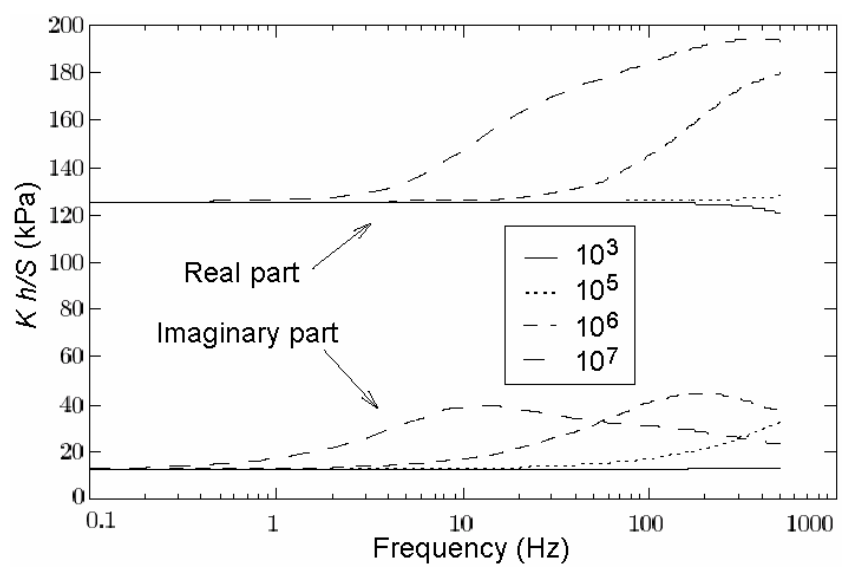

Figure 9. Predicted stiffness $K(\omega)$ for several air flow resistivities $\left(\mathrm{Nsm}^{-4}\right)$ of $10 \mathrm{~mm}$ thick porous sample.
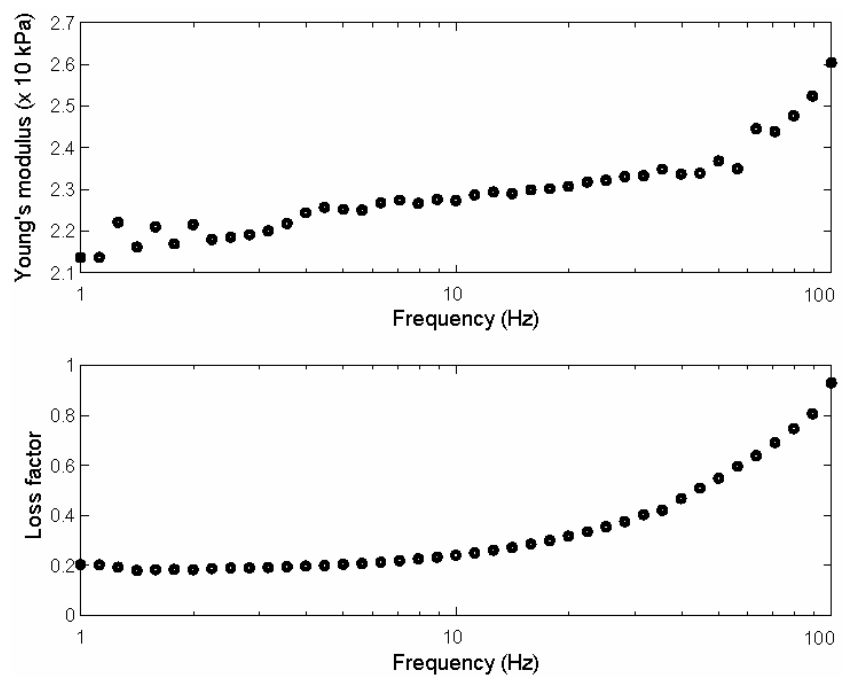

Figure 10. Measured Young's modulus and loss factor of 8.5 mm thick fibrous material.

\section{CONCLUSION}

This paper addresses the measurement of mechanical properties of acoustical porous materials by quasistatic method. It is shown that this technique is well suited for common material up to $100 \mathrm{~Hz}$. Restrictions occurs for thin samples of very high air flow resistivity and for fibrous material that do not exhibit a linear behaviour with static strain.

In order to get properties at higher frequencies, time temperature principle is being used for polymer foams (Etchessahar et al. 2002).

\section{REFERENCE}

Allard J.-F. 1993. Propagation of sound in porous media: modeling sound absorbing materials. Chapman \& Hall, London

Dauchez N., Sahraoui S. \& Atalla N. 2000. Experimental validation of 3-D poroelastic finite elements based on Biot theory. Internoise 2000, Nice

Etchessahar M., Benyahia L., Sahraoui S., Tassin J.-F. 2002. Viscoelastic properties of acoustic foams. Submitted to J. Acoust. Soc. Am.

Mariez E., Sahraoui S. 1997. Measurement of mechanical anisotropic properties of acoustic foams for the Biot model. Internoise 97, Budapest.

Melon M., Mariez E, Ayrault C. \& Sahraoui S. 1998. Acoustical and mechanical characterization of anisotropic open-cell foams. J. Acoust. Soc. Am. 104

Panneton R., Atalla N. 1997. An effcient finite element scheme for solving the three-dimensional poroelasticity problem in acoustics. J. Acoust. Soc. Am. 101: 3287-3298

Pritz T. 1986. Frequency dependance of dynamic characteristics of mineral and glass wool materials. J. Sound. Vib. 106(1): 161-169

Pritz T. 1994. Dynamic Young's modulus and loss factor of plastic foams for impact sound isolation. J. Sound. Vib. 173(3): 315-322

Sahraoui S., Mariez E. \& Etchessahar M. 2001a. Mechanical testing of polymeric foams at low frequency. Polymer Testing 20: 93-96

Sahraoui S., Mariez E. \& Etchessahar M. 2001b. Linear elastic properties of anisotropic open-cell foams. J. Acoust. Soc. Am. 110:635-637

Sfaoui A. 1995. On the viscoelasticity of the polyurethane foam. J. Acoust. Soc. Am. 97:1046-1052

Sides D.J., Attenborough K. \& Mulholland K.A. 1971. Application of a generalized acoustic propagation theory to fibrous absorbents. J. Sound. Vib. 19:49-64 